\title{
Is there a tectonically driven super-tidal cycle?
}

Green, Mattias; Molloy, Joseph; Davies, Hannah; Duarte, Joao

\section{Geophysical Research Letters}

DOI:

10.1002/2017GL076695

Published: 11/04/2018

Peer reviewed version

Cyswllt i'r cyhoeddiad / Link to publication

Dyfyniad o'r fersiwn a gyhoeddwyd / Citation for published version (APA):

Green, M., Molloy, J., Davies, H., \& Duarte, J. (2018). Is there a tectonically driven super-tidal cycle? Geophysical Research Letters, 45(8), 3568-3576. https://doi.org/10.1002/2017GL076695

\footnotetext{
Hawliau Cyffredinol / General rights

Copyright and moral rights for the publications made accessible in the public portal are retained by the authors and/or other copyright owners and it is a condition of accessing publications that users recognise and abide by the legal requirements associated with these rights.

- Users may download and print one copy of any publication from the public portal for the purpose of private study or research.

- You may not further distribute the material or use it for any profit-making activity or commercial gain

- You may freely distribute the URL identifying the publication in the public portal ?
}

Take down policy

If you believe that this document breaches copyright please contact us providing details, and we will remove access to the work immediately and investigate your claim. 


\title{
Is there a tectonically driven super-tidal cycle?
}

\author{
J. A. M. Green ${ }^{1}$, J. L. Molloy ${ }^{1,2}$, H. S. Davies ${ }^{3,4}$, and J. C. Duarte ${ }^{3,4,5}$ \\ ${ }^{1}$ School of Ocean Sciences, Bangor University, Menai Bridge, UK \\ ${ }^{2}$ Department of Geography, University of Sheffield, Sheffield, UK \\ ${ }^{3}$ Departamento de Geologia, Faculdade de Ciências, Universidade de Lisboa, Lisbon, Portugal \\ ${ }^{4}$ Instituto Dom Luiz (IDL), Faculdade de Ciências, Universidade de Lisboa, Lisbon, Portugal \\ ${ }^{5}$ School of Earth, Atmosphere and Environment, Monash University, Melbourne, Australia
}

\section{Key Points:}

- Earth is in a semi-diurnal tidal maximum and will go through another during the supercontinent cycle

- The average dissipation rates over the supercontinent cycle are lower than present rates

- This highlights a deep-time cycle of importance for past and future Earth system studies 


\section{Abstract}

Earth is $180 \mathrm{Myr}$ into the current Supercontinent cycle and the next Supercontinent is predicted to form in 250 Myr. The continuous changes in continental configuration can move the ocean between resonant states, and the semi-diurnal tides are currently large compared to the past 252 Myr due to tidal resonance in the Atlantic. This leads to the hypothesis that there is a "super-tidal" cycle linked to the Supercontinent cycle. Here, this is tested using new tectonic predictions for the next $250 \mathrm{Myr}$ as bathymetry in a numerical tidal model. The simulations support the hypothesis: a new tidal resonance will appear 150 Myr from now, followed by a decreasing tide as the supercontinent forms 100 Myr later. This affects the dissipation of tidal energy in the oceans, with consequences for the evolution of the Earth-Moon system, ocean circulation and climate, and implications for the ocean's capacity of hosting and evolving life.

\section{Introduction}

The Earth moves through a cyclic dispersion and aggregation of supercontinents over a period of 400-500 Myr, in what is known as the Supercontinent cycle [Nance et al., 1988; Rogers and Santosh, 2003; Matthews et al., 2016]. Pangea, the latest supercontinent, broke up around $180 \mathrm{Ma}$ [Golonka, 1991, 2007] and it is predicted that a new supercontinent will form over the next 200-250 Myr [e.g., Yoshida and Santosh, 2011; Duarte et al., 2018]. The break up of a supercontinent may lead to the formation of several internal oceans that will grow and eventually close. The lifecycle of each of these oceans is known as the Wilson Cycle [Wilson, 1966; Burke and Dewey, 1974]. Consequently, the completion of a Supercontinent cycle through the formation of a supercontinent is generally preceded by the termination of several Wilson cycles [e.g., Burke, 2011]. There is strong evidence that the tides are currently unusually large and that, for most of the current supercontinent cycle, they have been less energetic than at present [Kagan and Sundermann, 1996; Green et al., 2017]. The exception is the past 2 Myr, during which the continental configuration has led to a tidal resonance in the Atlantic [e.g., Platzman, 1975; Green, 2010]. This (near-)resonant state has led to increased global tidal dissipation rates, which were further enhanced during glacial low stands in sea-level [Egbert et al., 2004; Arbic and Garrett, 2010; Griffiths and Peltier, 2008; Green, 2010; Wilmes and Green, 2014; Green et al., 2017]. An ocean basin can house resonant tides when the width of the basin, $L$ is equal to a multiple of half-wavelengths, $\lambda=\sqrt{g H} T$ ( $\mathrm{T}$ is the tidal period, 
$g$ is gravity, and $H$ is water depth) of the tidal wave. Because today's resonant basin, the Atlantic, is currently opening we would expect it to move away from the resonant state as it continues to widen, if we assume that the water depth and tidal period remain constant. Later on during the Supercontinent cycle, we would expect either another basin to become resonant, either the Pacific if the Atlantic continues to open, or the Atlantic to become resonant again if it starts to close. This leads us to ask two questions: i) when and where does this second resonance occur, if at all, and ii) is there a super-tidal cycle, i.e., a cycle in the tidal amplitudes, associated with the supercontinent cycle? Here, the questions will be answered by new simulations of the possible evolution of the tide over the next 250 Myr. This is done by implementing the tectonic scenario in Duarte et al. [2018] as the bathymetric boundary condition in the tidal model described by Green et al. [2017].

Duarte et al. [2018] describe one possible scenario for the formation of the next supercontinent, Aurica, 250 Myrs into the future. Aurica is predicted to be fairly circular and located in the present day equatorial Pacific Ocean [see Duarte et al., 2018, and our Fig. 1]. It is formed by the closure of both the present day Atlantic and Pacific Oceans, which can only happen if a new ocean opens up. In the scenario, a bisection of Eurasia leads to the formation of a new ocean basin via intracontinental rifting. The motivation for the double-basin closure is that both the Atlantic and the Pacific oceanic lithospheres are already, in some regions, 180 Ma old [although the Pacific oceanic basin is much older; Golonka, 1991; Müller et al., 2008; Boschman and van Hinsbergen, 2016], and oceanic plates older than $200 \mathrm{Ma}$ are rare in the geological record [Bradley, 2011]. Consequently, it can be argued that both the Pacific and Atlantic must close to form the new supercontinent

Changes in the tides, and the associated tidal dissipation rates, on geological time scales have had profound implications for the Earth system. Herold et al. [2012] and Green and Huber [2013] show that the changed location of abyssal tidal dissipation during the Eocence (55 Ma) can explain the reduced meridional temperature gradients seen in the proxy record for sea-surface temperature that coupled climate models have struggled to reproduce [see Herold et al., 2012, for a summary]. Furthermore, the reduced tidal dissipation during the Mesozoic and Cenozoic eras reported by Green et al. [2017] had implications for lunar recession rates, and hence for interpreting cyclostratigraphy and long-term climate cycles [Waltham, 2015], for the evolution of the Earth-Moon system [Green et al., 2017], and for the evolution of life [Balbus, 2014]. 
The disposition of the continents on Earth over geological time scales consequently has a direct and major impact in the evolution of the Earth-Moon System, and tidal dissipation should be included in global ocean- and climate models, especially over long-timescales [Green and Huber, 2013]. The overall aim of this paper is to evaluate if there is a super-tidal cycle linked to the Supercontinent cycle. We do this by expanding the work of Green et al. [2017] by adding tidal simulations 250 Myr into the future using the tectonic
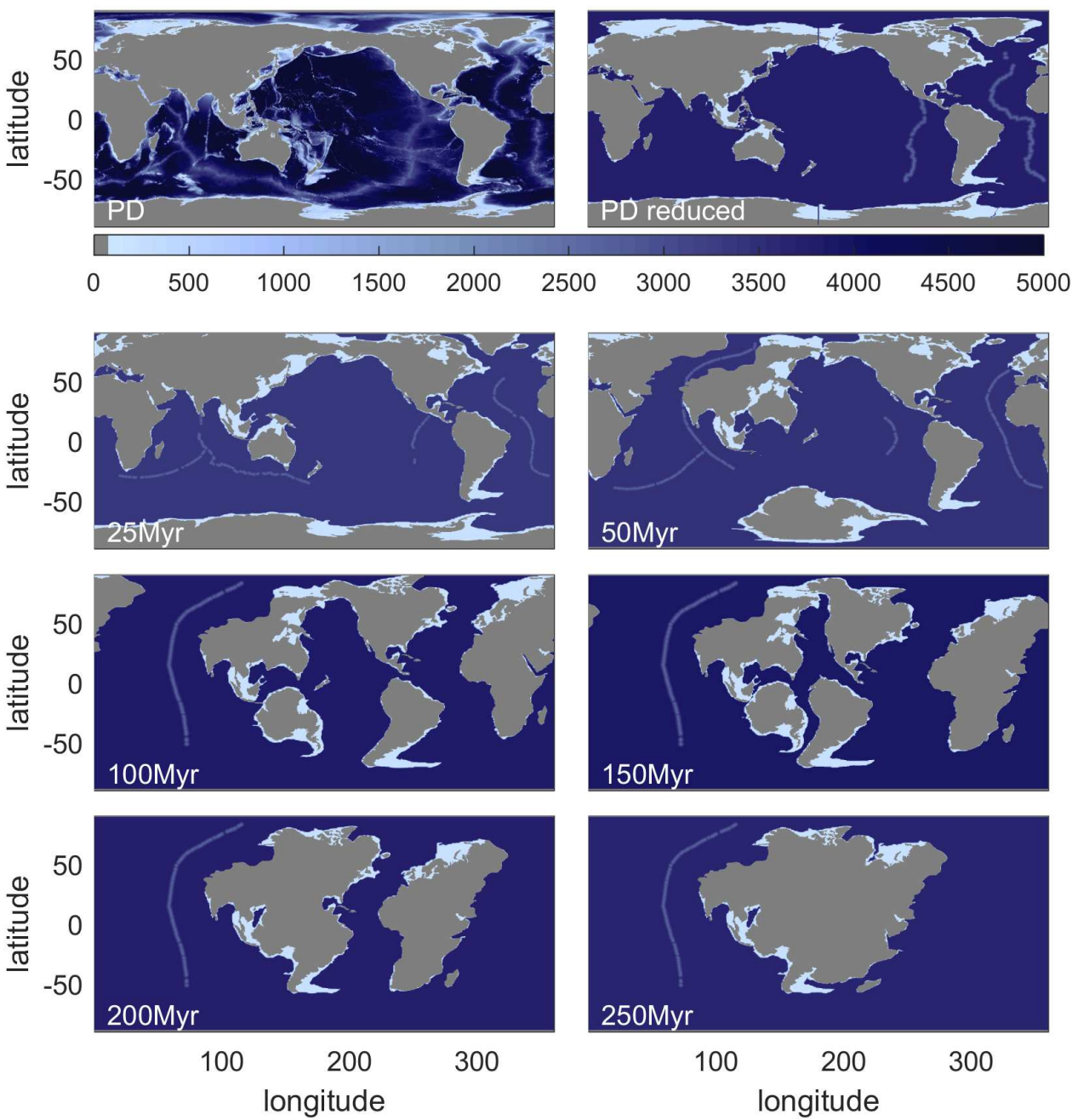

Figure 1. Shown is the tectonic evolution and eventual formation of the next supercontinent, Aurica. The top two panels show present day (PD) and PD reduced bathymetries, respectively (see methods for details). The timings for the other slices are noted in the lower left corner of each panel. The colours mark the depths used in the tidal model simulations: light blue is $200 \mathrm{~m}$, intermediate blue is $2500 \mathrm{~m}$, and the majority of the ocean is less than $4000 \mathrm{~m}$ deep (see methods below for details). 
predictions in Duarte et al. [2018] as bathymetric boundary conditions. Consequently, this paper will increase our fundamental understanding of the Earth system, and it will, if the hypothesis is correct, lead to a first-order predictability of when large supertides may occur in Earth's history. To obtain this knowledge, we want to cover a full supercontinent cycle to see if there is a super-tidal cycle. The logical thing to do is to expand the supercontinent cycle we are currently in into the future, because the first part of it has already been covered and shown to be tidally less energetic than PD [Green et al., 2017]. In the next section we describe the tidal model and the bathymetric time-slices used to obtain the results in section 3. Section 4 closes the paper with a discussion and conclusions, and an outlook in to further work.

\section{Modelling future tides}

\subsection{Tides}

We use OTIS - the Oregon State University Tidal Inversion Software - to simulate the evolution of the future tides. OTIS is a portable, dedicated, numerical shallow water tidal model, which has been used extensively for both global and regional modelling of past, present and future ocean tides [e.g., Egbert et al., 2004; Green, 2010; Pelling and Green, 2013; Green and Huber, 2013; Wilmes and Green, 2014; Green et al., 2017]. It is highly accurate both in the open ocean and in coastal regions [Stammer et al., 2014], and it is computationally efficient. The model solves the linearised shallow-water equations [e.g., Hendershott, 1977]:

$$
\begin{array}{r}
\frac{\partial \mathbf{U}}{\partial t}+\mathbf{f} \times \mathbf{U}=-g H \nabla\left(\zeta-\zeta_{E Q}-\zeta_{S A L}\right)-\mathbf{F} \\
\frac{\partial \zeta}{\partial t}=-\nabla \cdot \mathbf{U}
\end{array}
$$

Here $\mathbf{U}$ is the depth integrated volume transport (i.e., tidal current velocity $\mathbf{u}$ times water depth $H), f$ is the Coriolis vector, $g$ denotes the gravitational constant, $\zeta$ is the tidal elevation and $\zeta_{S A L}$ denotes the tidal elevation due to self-attraction and loading (SAL), and $\zeta_{E Q}$ is the equilibrium tidal elevation. For simplicity we used a constant SAL correction with $\beta=0.1$ [Egbert et al., 2004]. $\mathbf{F}$ represents energy losses due to bed friction and tidal conversion. The former is represented by the standard quadratic law:

$$
\mathbf{F}_{B}=C_{d} \mathbf{u}|\mathbf{u}|
$$

where $C_{d}=0.003$ is a drag coefficient, and $\mathbf{u}$ is the total velocity vector for all the tidal constituents. The conversion, $\mathbf{F}_{w}=C|\mathbf{U}|$, includes a conversion coefficient $C$, which is 
here defined as [Zaron and Egbert, 2006; Green and Huber, 2013]

$$
C(x, y)=\gamma \frac{(\nabla H)^{2} N_{b} \bar{N}}{8 \pi^{2} \omega}
$$

Here, $\gamma=50$ is a scaling factor, $N_{b}$ is the buoyancy frequency at the sea-bed, $\bar{N}$ is the vertical average of the buoyancy frequency, and $\omega$ is the frequency of the tidal constituent under evaluation. The buoyancy frequency is given by $N=N_{0} \exp (-z / 1300)$, where $N_{0}=5.24 \times 10^{-3} \mathrm{~s}^{-1}$ and based on a least squares fit to present day climatology values [Zaron and Egbert, 2006]. The future stratification is obviously unknown, and to estimate potential effects of altered stratificaiton we did a set of sensitivity simulations in which $C$ was doubled or halved. As in other tidal simulations this had a relatively minor effect on the global tides, and we will not discuss these results further [see, e.g., Egbert et al., 2004; Green and Huber, 2013].

The model solves equations (1)-(2) using the astronomic tide generating force as the only forcing (represented by $\zeta_{E Q}$ in Eq. (1)). An initial spin-up from rest of over 7 days is followed by a further 5 days of simulation time, on which harmonic analysis is performed to obtain the tidal elevations and transports. Here, we focus on the $\mathrm{M}_{2}$ and $\mathrm{K}_{1}$ constituents only.

\subsection{Bathymetry data}

\subsubsection{Present Day bathymetries}

The Present Day (PD) bathymetry is the same as in Green et al. [2017]: see our Fig. 1, top left panel. To avoid open boundaries, the equilibrium tide was used as forcing at $88^{\circ}$ when appropriate. Tests with a vertical wall at the poles (not shown) did not change the results. All simulations were done with $1 / 4^{\circ}$ horizontal resolution. The PD control simulation was compared to the elevations in the TPXO8 database and the root mean square errors (RMSEs) was computed from the difference between modelled and observed elevations. TPXO8 is an inverse tidal solution for both elevation and velocity based on satellite altimetry and the shallow water equations, and is commonly taken as the thruth for tidal elevations [see Egbert and Erofeeva, 2002, and http://volkov.oce.orst.edu/tides/tpxo8_atlas.html for details].

To evaluate the sensitivity of our solutions to the lack of detail in the future bathymetries, we constructed a simplified PD bathymetry having the same (lack of) detail as the 
future bathymetries (see Fig. 1, top right panel). This case is denoted PD reduced in the following, and it is the simulation we use as a benchmark for the evolution of the tide. In PD reduced any water currently shallower than $200 \mathrm{~m}$ was set to $200 \mathrm{~m}$. PD oceanic ridges were smoothed out and set to have a peak depth of $2500 \mathrm{~m}$ and a total width of $5^{\circ}$ degrees over which the ridge approaches the depth of the deep ocean linearly, whereas subduction zones were set to be $1^{\circ}$ wide and $6000 \mathrm{~m}$ deep with a triangular cross-section. The remaining ocean was set to a depth computed to conserve the ocean's present day total volume. The same values were used in the construction of the future bathymetries shown in Fig. 1.

\subsubsection{Future bathymetries}

We used GPlates for the kinematic tectonic modelling of the future scenario [see Qin et al., 2012; Duarte et al., 2018, and https://www.gplates.org/ for a description]. The continental polygons provided in the GPlates data repository were used as the starting point for the present day ocean, as in Matthews et al. [2016]. The drift paths of the continental plates were constrained for the first $25 \mathrm{Myr}$ by the drift velocities in Schellart et al. [2007]. For the remaining $225 \mathrm{Myr}$, we used the PD globally averaged plate velocity of $5.6 \mathrm{~cm} \mathrm{yr}^{-1}$ [see Duarte et al., 2018, for a summary], but applied deviations from the average based on the observations in Zahirovic et al. [2016]. The plate- and land boundaries from the model were output as digital greyscale images, which were used to build the model bathymetries based on the details given for the PD sensitivity bathymetry.

\subsection{Dissipation computations}

The computation of tidal dissipation rates, D, was done following Egbert and Ray [2001] and thus given by

$$
D=W-\nabla \cdot P .
$$

Here, $W$ is the work done by the tide-generating force and $P$ is the energy flux given by

$$
\begin{aligned}
W & =g \rho\left\langle\mathbf{U} \cdot \nabla\left(\eta_{S A L}+\eta_{E Q}\right)\right\rangle \\
P & =g\langle\eta \mathbf{U}\rangle
\end{aligned}
$$

where the angular brackets mark time-averages over a tidal period. 


\section{Results}

\subsection{Present Day sensitivity}

The PD control simulation (Fig. 2, top left) has an RMSE of $11 \mathrm{~cm}$ when compared to TPXO8; the same computation for the reduced M2 tide give $23 \mathrm{~cm}$. The K1 RMSE are $2 \mathrm{~cm}$ for PD and $10 \mathrm{~cm}$ for PD reduced, respectively. As discussed above, we did a series of sensitivity simulations for both bathymetries in which the tidal conversion coefficient was changed within a factor of 2, and the RMSE and dissipation rates did not change sig-
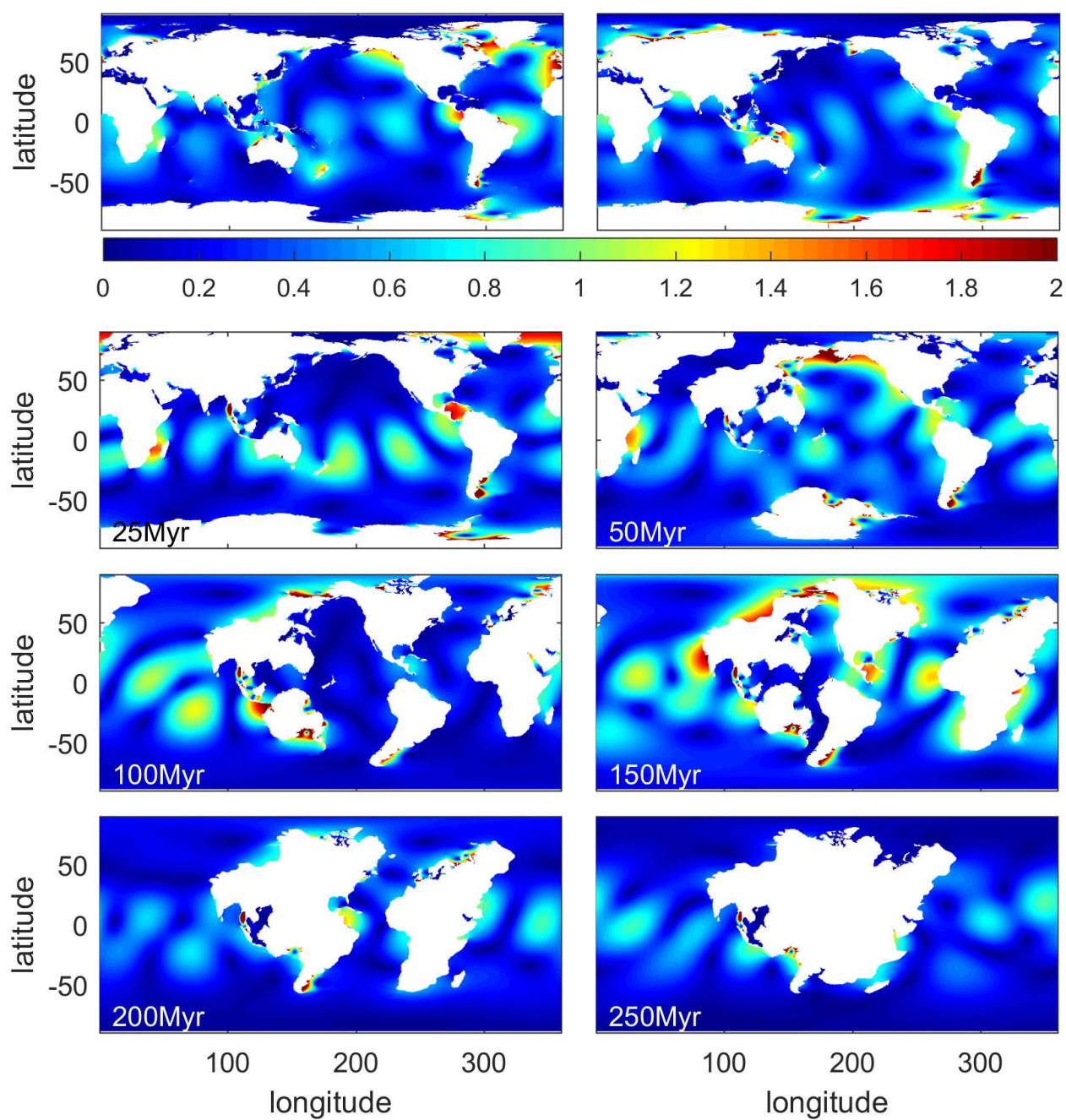

Figure 2. Shown are the M2 tidal amplitudes, in meters, for the PD (top left) and PD reduced (top right) simulations, along with the future time slices. Note that the colour scale saturates in the more energetic scenarios. 
nificantly (not shown). Green and Huber [2013] and Green et al. [2017] did an extensive series of sensitivity simulations and came to the same conclusion. Consequently, we have confidence in the robustness of our results, and we have a well-constrained error bound on the simulations.

The PD sensitivity simulation reveals a less energetic global tide (Fig. 2, top right), with reduced M2 tidal amplitudes in the Atlantic and the emergence of fairly large M2 tides along the Siberian shelf and around Antarctica. The new tides along the northern coast of Eurasia are due to the sub-arctic seas being deeper, allowing the tide to propagate into the Arctic Basin. The large PD Atlantic tides are reduced because of the water-world like ocean and reduced shelf sea area, leading to a more equilibrium-like tide [see $E g$ bert et al., 2004, for a discussion]. The weaker M2 tide in the PD reduced scenario means that we are potentially underestimating the M2 amplitudes for all future scenarios. For K1 we see a different pattern in Fig. 3 (top row panels): our synthetic bathymetry appears to produce a larger K1 amplitude than the PD bathymetry. This is likely because the changed water depth allow the K1 tide to be nearer resonance in some areas, such as around Greenland and Indonesia. It is thus possible that we are overestimating K1 in the future scenarios. Note that this is a reversed response to that in Green et al. [2017], where their simplified bathymetry gives an enhanced M2 tide. The bathymetries in Green et al. [2017], however, have more topographic detail, especially in shallow water, than the ones used here. For clarity, we will describe our globally averaged or integrated metrics in relative terms by normalising by the respective values from the simplified PD bathymetry.

\subsection{Tidal amplitudes}

The global M2 tidal amplitude increases slightly over the next $50 \mathrm{Myr}$ (refer to Fig. 2 and Fig. 4a for the following discussion) due to an enhanced tide in the North Atlantic and Pacific at $25 \mathrm{Myr}$, followed by a very large Pacific tide at 50 Myr. This is because the equatorial Pacific becomes half-wavelength resonant at these ages. At $100 \mathrm{Myr}$, there are large tides in the newly formed Pan-Asian Ocean (in the Asian rift) and in the Indian Ocean. This signal persists to $150 \mathrm{Myr}$ when the Atlantic comes back into resonance to form the next tidal maximum. After $150 \mathrm{Myr}$, there is a decline of the global amplitudes as the new supercontinent starts to come together and the resonant properties 
of the basins are lost. When Aurica has formed fully at $250 \mathrm{Myr}$, we only see large tides locally, in embayments with a geometry allowing for local resonances.

K1 follows a different pattern to M2, with a global tidal maximum when M2 hits a minimum at $100 \mathrm{Myr}$ (the maximum $\mathrm{K} 1$ amplitude is then about $5 \mathrm{~m}$ ). The average $\mathrm{K} 1$ amplitude remains relatively constant between 150-200 Myr, before a very sharp decline as the next continent forms (Figs. 3 and 4a). It appears that $\mathrm{K} 1$ does not have two resonances in this tectonic scenario, whereas M2 does, because it becomes resonant again when the Atlantic closes, as well as in what is left of the Pacific at $150 \mathrm{Myr}$ (Fig. 2). This
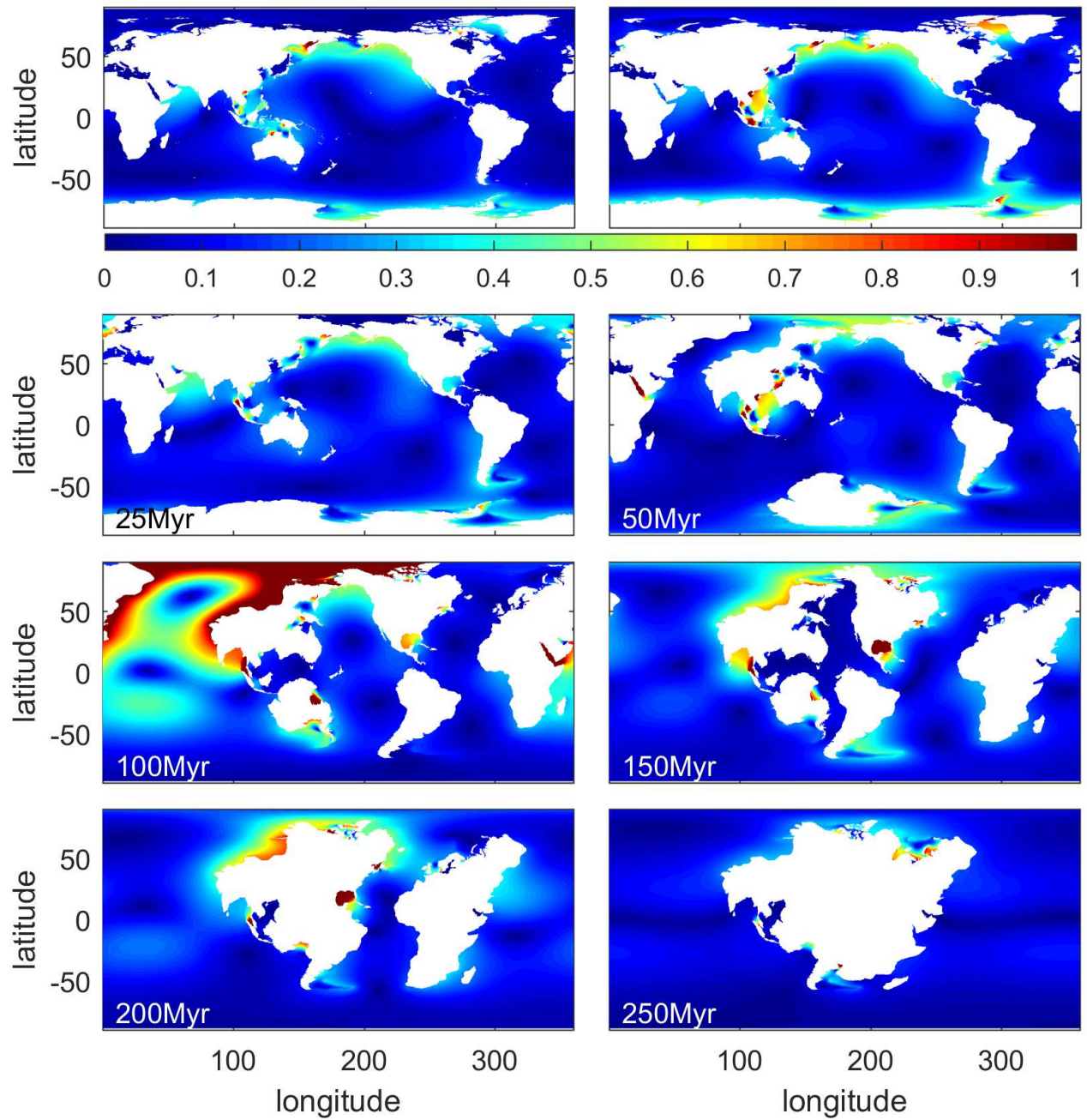

Figure 3. As in Fig. 2, but showing K1 amplitudes (again in meters). Note the different color scale between this figure and Fig. 2. 
makes sense from a basin size perspective: because the Atlantic continues to open for a while before closing again, K1 will never have an opportunity to become resonant in the Atlantic, whereas M2 will be. Because of the changing size of the Pacific, it will be resonant for the K1 tide at 100 Myr only.

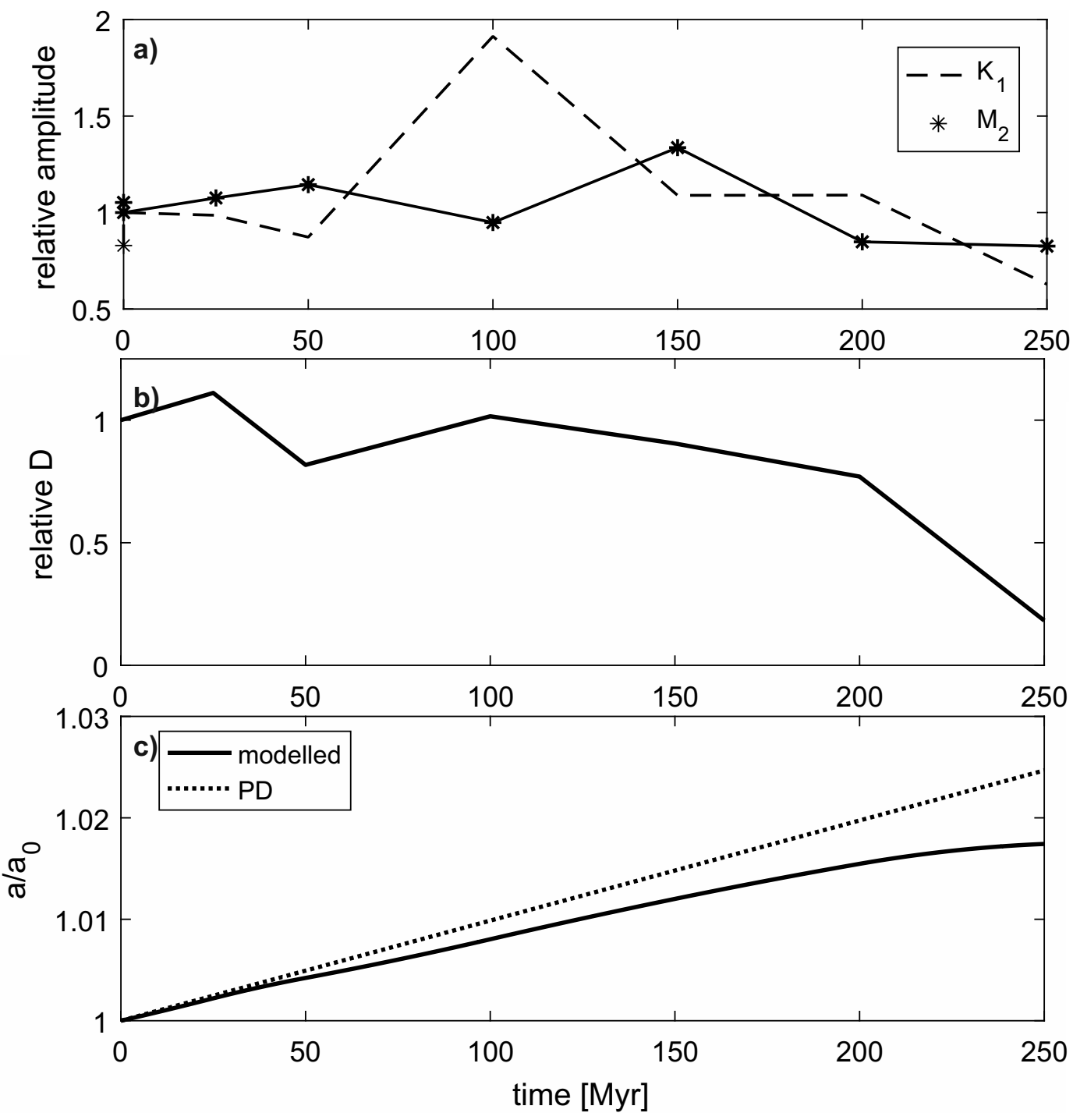

Figure 4. a) Shown are time series of the evolution of the tidal constituents. The solid line, with markers, represents the globally averaged M2 amplitude, whereas the dashed line shows K1 amplitudes.

b) Globally integrated M2 tidal dissipation rates normalised with the PD dissipation.

c) The evolution of the lunar distance, $a$, over time using the dissipation in panel $\mathrm{b}$ (solid) and the PD dissipation rate (dashed). Both are computed from Eqs. (8)-(9). The distance is normalised by the PD distance, $a_{0}$. 


\subsection{Dissipation and Earth-Moon evolution}

Overall, the global M2 dissipation rates for the remainder of the Supercontinent cycle is $84 \%$ of the present values, or 2.2 TW (Fig. 4b). This expands the results in Green et al. [2017] $250 \mathrm{Myr}$ into the future, and strongly suggests that Earth is presently in an M2 tidal maximum. It also suggests that the maximum has a width of $50 \mathrm{Myr}$ or less, and that there will be another M2 maximum occurring during the cycle around $150 \mathrm{Myr}$ from now, i.e., $100 \mathrm{Myr}$ before the formation of the next supercontinent. K1, in contrast, will be resonant only once in the current cycle, at 100 Myr. This is in agreement with results for the late Silurian (430 Ma), which show more energetic tides than during the Early Devonian [400 Ma; H. Byrne, pers. comm. and Balbus, 2014]. Pangea, the previous supercontinent, formed around $330 \mathrm{Myr}$ ago and started breaking up some $180 \mathrm{Myr}$ ago. It thus seems plausible that Earth's oceans go through tidal maxima some 150-200 Myr after supercontinental break up (i.e., at present) and around $100 \mathrm{Myr}$ before a supercontinent forms (i.e., during the Silurian, before Pangea, and 150 Myr into the future for Aurica).

Following the theory of lunar recession in Waltham [2015] and summarised in Green et al. [2017], the recession rate, $\partial a / \partial t$, can be written as

$$
\frac{\partial a}{\partial t}=f a^{-5.5}
$$

where $f$ is the tidal factor given by

$$
f=\frac{2 D a^{6}}{m^{\prime} \sqrt{\omega^{2} a^{3}}(\Omega-\omega)}
$$

$$
\text { Here, } m^{\prime}=m M /(m+M) \text { is the reduced mass of the Moon }\left(M=5.972 \times 10^{24} \mathrm{~kg}\right.
$$
and $m=7.348 \times 10^{22} \mathrm{~kg}$ are the masses of the Earth and the Moon, respectively), and $\Omega=7.2923^{-5} \mathrm{~s}^{-1}\left(\omega=2.6616 \times 10^{-6}\right) \mathrm{s}^{-1}$ is the rotation rate of the Earth (Moon). Using the dissipation rates in Fig. 4b, interpolated to every 1 Myr using linear interpolation to produce a smoother curve, we obtain the result in Fig. 4c. We have also, for comparison, computed the lunar distance assuming a continuous PD dissipation rate (dashed). These results further highlight the conclusions in Green et al. [2017], that appropriate tidal dissipation rates should be used in investigations involving lunar recession rates or distances, especially over long periods of time. Consequently, the PD recession rate is anomalously high because of the current tidal resonance in the Atlantic, and that PD tides are a poor proxy for past or future tides over large parts of the Supercontinent cycle. 


\section{Discussion}

Our results support previous ideas that the tides are at their lowest when the Earth is in the supercontinent configuration. The dissipation is then less than $40 \%$ of the PD value in our simulations. The tenure of a supercontinent varies, but both Pangaea and Rodinia, the two most recent supercontinents, maintained their formation for over $100 \mathrm{Myr}$ [Rogers and Santosh, 2003]. This means that dissipation rates could remain at this very low level for long periods of time - much longer than the time-scale of its resonant peaks, which here are less than $50 \mathrm{Myr}$ (see below for a tighter constraint).

This project aimed to evaluate if there is a super-tidal cycle. The results strongly suggests that the answer is yes: there is a repeated gradual change between states of high and low tidal dissipation levels over the period of Aurica forming. However, there is more than one super-tidal cycle within the Supercontinent cycle. Combined with the results in Green et al. [2017], who goes back to Pangea $252 \mathrm{Myr}$ ago, we suggest the oceans will go through two M2 super-tidal cycles and at least one K1 cycle during the current Supercontinent cycle. Consequently, the global tides are weak for long periods of time, and then pass through several quite narrow (on geological time scales) resonances. This is because there are several Wilson cycles involved in one supercontinent cycle, and as the basins open and close there can be several super-tidal cycles associated with the Wilson Cycles. This also means that the super-tidal cycle is not necessarily in phase with the supercontinent cycle. The mechanism behind the super-tidal cycle is tidal resonance, which is set up by the continental configurations: peak resonance occurs when the continental configuration results in an ocean basin of a length that is an exact multiple of half wavelengths of the M2 tidal wave. Theoretically, one would therefore be able to predict when each basin may be resonant, without being able to provide any details of the actual magnitude. To lowest order, one can assume that the tide will be large when the natural frequency of a basin is within, say, $20 \%$ of the tidal period [see Fig. 11 in Egbert et al., 2004, for a theoretical estimate]. For the present, this would give a period window of about 3 hours in which the basin is close enough to resonance to support a large tide. If the ocean is 4000 $\mathrm{m}$ deep and we are looking at a half-wavelength resonance, we get a range of the width of the basin in which it is resonant of about $1100 \mathrm{~km}$. With a continental drift rate of 6 $\mathrm{cm} \mathrm{yr}^{-1}$, the width of the resonant peak would then be some $18 \mathrm{Myr}$, implying that Earth is currently in the beginning of the tidal maximum. There is further support for this in our results here and in Green et al. [2017]. They show that the tides were weak $2 \mathrm{Myr}$ before 
present, and the $25 \mathrm{Myr}$ time slice in the present paper still shows a rather large tide. This is an interesting idea worth pursuing in a future paper, which would look into the time span of the resonances in more detail by simulating more time slices between now and 25 Myr.

Ocean basin closure is a result of consumption of oceanic plate at subduction zones within the basin and sea floor spreading in a neighbouring basin. This means that there are long periods where the direction of closure is mostly fixed, with two continental plates being pulled or pushed together. The observation that there are multiple peaks in tidal dissipation makes sense in this context. There will be multiple modes of resonance for each ocean basin as it reaches the dimensions that are resonant for smaller or larger multiples of the tidal wavelength. The implication of these observations is that the length of a super-tidal cycle is directly related to the length of the supercontinent cycle. Consequently, the period of the super-tidal cycle is set by how quickly the continental configurations moves from one resonant mode to another. There are of course other factors that contribute to the total tidal dissipation, such as sea level changes and variations in the extent of continental shelves, but through this study we have a clear indication that changing the position of the continents alone is enough to elicit significant changes in the energy of the tidal system. However, if an ocean basin is close to resonance it is much more sensitive to relative sea-level changes and/or continental shelf configurations than when its not in a near-resonant state. This was the case for the Last Glacial Maximum (21-18 kyr) where Green et al. [2017] find the largest M2 amplitude in their 252 Myr time series. This exceptionally large tide is explained by a low-stand in sea-level, exposing the dissipative shelf seas [Egbert et al., 2004; Wilmes and Green, 2014].

The results here are promising, and further investigations will focus on other tectonic scenarios and increasing the temporal resolution of our simulations. This will provide a further understanding of the future Earth system, and will, along with more simulations of the past, allow us to build a better picture of the variability in tides and tidal dissipation rates over long time periods.

\section{Acknowledgments}

JAMG acknowledges funding from the Natural Environmental Research Council through grants NE/F014821/1 and NE/I030224/1. JCD acknowledges an FCT Researcher contract, an exploratory project grant Ref. IF/00702/2015, and the FCT-project UID/GEO/50019/2013- 
IDL. HSD was supported by FCT (ref. UID/GEO/50019/2013 - Instituto Dom Luiz; FCT PhD grant, ref. PD/BD/135068/2017). Kara Matthews (Oxford University) provided invaluable support on using GPlates. Comments from Sophie Wilmes, Jeroen Ritsema (editor), Dietmar Müller (reviewer), and an anonymous reviewer greatly improved the manuscript.

The data is available from the Open Science Framework (osf.io/8ydwv).

\section{References}

Arbic, B. K., and C. Garrett (2010), A coupled oscillator model of shelf and ocean tides, Continental Shelf Research, 30, 564-574.

Balbus, S. A. (2014), Dynamical, biological and anthropic consequences of equal lunar and solar angular radii, Proceeding of the Royal Society of London, A, 470, 20140,263.

Boschman, L. M., and D. J. J. van Hinsbergen (2016), On the enigmatic birth of the Pacific Plate within the Panthalassa Ocean, Science Advances, 2, e1600,022.

Bradley, D. (2011), Secular trends in the geologic record and the supercontinent cycle, Earth-Science Reviews, 108, 16-33.

Burke, K. (2011), Plate tectonics, the wilson cycle, and mantle plumes: Geodynamics from the top, Annual Review of Earth and Planetary Sciences, 39, 1-29.

Burke, K., and J. F. Dewey (1974),Hot spots and continental breakup: implications for collisional orogeny, Geology, 2, 57-60.

Duarte, J., W. Schellart, and F. Rosas (2018), The future of earth's oceans: Consequences of subduction initiation in the atlantic and implications for supercontinent formation, Geological Magazine, 155, 45-58.

Egbert, G. D., and S. Erofeeva (2002), Efficient inverse modeling of barotropic ocean tides, Journal of Atmospheric and Oceanic Technology, 19, 183-204.

Egbert, G. D., and R. D. Ray (2001), Estimates of M2 tidal energy dissipation from Topex/Poseidon altimeter data, Journal of Geophysical Research, 106, 22,475-22,502.

Egbert, G. D., B. G. Bills, and R. D. Ray (2004), Numerical modeling of the global semidiurnal tide in the present day and in the last glacial maximum, Journal of Geophysical Research, 109, C03,003, doi: 10.1029/2003JC001,973.

Golonka, C. R. (1991), Jurassic and cretaceous plate tectonic reconstructions, Paleogeography, Palaeoecology, Palaeoclimatology, 87, 493-501.

Golonka, J. (2007), Late triassic and early jurassic palaeogeography of the world, Paleogeography, Palaeoecology, Palaeoclimatology, 244, 297-307. 
Green, J., M. Huber, D. Waltham, J. Buzan, and M. Wells (2017), Explicitly modeled deep-time tidal dissipation and its implication for lunar history, Earth and Planetary Science Letters, 461, 46-53.

Green, J. A. M. (2010), Ocean tides and resonance, Ocean Dynamics, 60, doi: 10.1007/s10236-010-0331-1.

Green, J. A. M., and M. Huber (2013), Tidal dissipation in the early Eocene and implications for ocean mixing, Geophysical Research Letters, 40, doi:10.1002/grl.50,510.

Griffiths, S. D., and W. R. Peltier (2008), Megatides in the Arctic Ocean under glacial conditions, Geophysical Research Letters, 35, L08,605, doi:10.1029/2008GL033,263.

Hendershott, M. C. (1977), Numerical models of ocean tides, in The Sea vol. 6, pp. 47-89, Wiley Interscience Publication.

Herold, N., M. Huber, R. D. MÃijller, and M. Seton (2012), Modeling the miocene climatic optimum: Ocean circulation, Paleoceanography, 27, PA1209.

Kagan, B., and A. Sundermann (1996), Dissipation of tidal energy, paleotides, and evolution of the earth-moon system, Advances in Geophysics, 38, 179-266.

Matthews, K., K. Maloney, S. Zahirovic, S. Williams, M. Seton, and R. D. MÃijller (2016), Global plate boundary evolution and kinematics since the late paleozoic, Global and Planetary Change, 146, 226-250.

Müller, R. D., M. Sdrolias, C. Gaina, and W. R. Roest (2008), Age, spreading rates, and spreading asymmetry of the world's ocean crust, Geochemistry, Geophysics, Geosystems, 9, Q04006.

Nance, R. D., T. R. Worsley, and J. B. Moody (1988), The supercontinent cycle, Scientific American, 256, 72-79.

Pelling, H. E., and J. A. M. Green (2013), Sea-level rise, tidal power, and tides in the Bay of Fundy, Journal of Geophysical Research, 118, 1-11.

Platzman, G. W. (1975), Normal modes of the Atlantic and Indian Oceans, Journal of Physical Oceanography, 5, 201-221.

Qin, X., R. Muller, J. Cannon, T. Landgrebe, C. Heine, R. Watson, and M. Turner (2012), The gplates geological information model and markup language, Geoscientific Instrumentation, Methods and Data Systems, 1, 111-134.

Rogers, J., and M. Santosh (2003), Supercontinents in earth history, Gondwana Research, 6, 357-368, doi:10.1016/S1342-937X(05)70993-X. 
Schellart, W. P., J. Freeman, D. R. Stegman, L. Moresi, and D. May (2007), Evolution and diversity of subduction zones controlled by slab width, nature, 446, 308-311.

Stammer, D., R. D. Ray, O. B. Andersen, B. K. Arbic, W. Bosch, L. CarrÃÍre, Y. Cheng, D. S. Chinn, B. D. Dushaw, G. D. Egbert, S. Y. Erofeeva, H. S. Fok, J. A. M. Green, S. Griffiths, M. A. King, V. Lapin, F. G. Lemoine, S. B. Luthcke, F. Lyard, J. Morison, M. MÃijller, L. Padman1, J. G. Richman, J. F. Shriver, C. K. Shum, E. Taguchi, and Y. Yi (2014), Accuracy assessment of global ocean tide models, Reviews of Geophysics, 52, doi:10.1002/2014RG000,450.

Waltham, D. (2015), Milankovitch period uncertainties and their impact on cyclostratigraphy, Journal of Sedimentary Research, 85, 990-998.

Wilmes, S.-B., and J. A. M. Green (2014), The evolution of tides and tidally driven mixing over 21,000 years, Journal of Geophysical Research, 119, doi:10.1002/2013JC009,605.

Wilson, J. T. (1966), Did the Atlantic Close and then Re-Open? Nature, 211, 676-681.

Yoshida, M., and M. santosh (2011), Future supercontinent assembled in the northern hemisphere, Terra Nova, 23, 333-338.

Zahirovic, S., K. J. Matthewsa, N. Flamenta, R. D. Müller, K. C.Hill, M. Seton, and M. Gurnis (2016), Tectonic evolution and deep mantle structure of the eastern tethys since the latest jurassic, Earth-Science Reviews, 162, 293-337.

Zaron, E. D., and G. D. Egbert (2006), Estimating open-ocean barotropic tidal dissipation: The Hawaiian Ridge, Journal of Physical Oceanography, 36, 1019-1035. 